\title{
App-Tailoring Requirements to Increase Stress Management Competencies Within Families: Cross-sectional Survey Study
}

Laura Luise Bischoff ${ }^{1}$, MA; Hannes Baumann ${ }^{1}$, MEd; Charlotte Meixner ${ }^{1}$, MA; Patricia Nixon ${ }^{2}$, MSc; Bettina Wollesen $^{1,3}$, Prof Dr

\footnotetext{
${ }^{1}$ Department of Movement Science, Faculty of Psychology and Human Movement, University of Hamburg, Hamburg, Germany

${ }^{2}$ Fitbase Institute for Online Prevention GmbH, Hamburg, Germany

${ }^{3}$ Biopsychology and Neuroergonomics, Technical University of Berlin, Berlin, Germany
}

\section{Corresponding Author:}

Laura Luise Bischoff, MA

Department of Movement Science

Faculty of Psychology and Human Movement

University of Hamburg

Mollerstraße 10

Hamburg, 20148

Germany

Phone: 49404283893

Email: laura.bischoff@uni-hamburg.de

\section{Abstract}

Background: Families experiencing high levels of psychological distress are considered a particularly vulnerable population for adverse effects on mental and physical health. Moreover, highly stressed individuals engage less in mental health promoting activities and show low stress management competencies. App-based stress interventions seem promising for the treatment and prevention of stress outcomes and might be a low-threshold solution.

Objective: The aim of this study was to identify the requirements for a tailored app to reduce stress in a cohort of highly stressed families that have low stress management skills.

Methods: Parents (n=1008; age: mean 47.7 years, SD 6.1; female: 599/1008, 59.7\%) completed an extensive web-based survey and were subdivided into a target (stressed individuals with low stress competency) and nontarget group according to their reported stress level and stress management competencies. Group differences were analyzed using analysis of variance. In principal component analysis with Kaiser varimax rotation, personally defined stress management goals were grouped into components. Linear regression models were also calculated.

Results: A 3-factor solution cumulatively explained $56 \%$ of the variance in personally defined goals of interest for stress management with (1) active strategies (25.61\% explained variance), (2) general competency (17.95\% explained variance) and (3) passive strategies $\left(12.45 \%\right.$ explained variance). The groups differed in age $\left(F_{1,978}=27.67, P<.001\right)$, health index $\left(F_{1,958}=246.14\right.$, $P<.001)$, personally defined general-competency goal $\left(F_{1,958}=94.16 P<.001\right)$, as well as "information acquisition" $\left(F_{1,971}=14.75\right.$, $P<.001)$ and "need for stimulation" $\left(F_{1,981}=54.49, P<.001\right)$ personality traits. A regression model showed that for the active strategies goals of interest, only app feature information or instructional videos had a significant effect $(P=.02)$. The general competency factor showed none, and the passive strategies factor showed significant effects for 2 app features-suggestions for planning possible activities with the family $(P=.01)$ and diaries for documentation and development of strategies $(P=.03)$.

Conclusions: The results of this survey study highlight the need to develop an app to increase stress management competencies that takes into consideration perceived stress level, stress management skills, personality, and personally defined goals of the user. The content of the app should be tailored to previously detected personality traits, especially selective information acquisition and low need for stimulation. Furthermore, personally defined stress management goals seem to affect interest in some features.

(J Med Internet Res 2021;23(7):e26376) doi: $\underline{10.2196 / 26376}$

\section{KEYWORDS}

mhealth; ehealth; mobile applications; stress management; app features; gamification; family; personality traits 


\section{Introduction}

\section{Background}

Stress is associated with heightened risks of adverse physical and mental health consequences, such as impaired sleep [1], gastrointestinal diseases [2], diabetes [3], coronary heart disease [4], or depression [5]. These consequences are a tremendous burden from a societal, personal, and economical perspective. Families experiencing high levels of psychological distress are considered a vulnerable population [6]. Melchior et al [7] found, for example, that participants who are simultaneously exposed to elevated levels of work stress and high family demands have heightened rates of sickness absence due to psychiatric disorders. Studies investigating work-family spillover effects show that perceived stress at work can be transferred to family members [8-10]. In accordance with the work-family spillover theory, parents play a significant role in their children's health and coping by implementing or reinforcing certain behaviors $[11,12]$. Family stress was, for example, predictive of less adequate child dietary intake, with one effect occurring indirectly via impaired parent-child relationship quality [13]. In general, health is subject to sociostructural and milieu-specific dependencies for which the family is an important influencing factor [14-18]. It, therefore, seems to be of the utmost importance to create effective interventions to manage high stress levels in families.

\section{Stress Management Competencies}

An increasing amount of literature suggests that interventions using different stress management techniques, such as mindfulness, lead to significant psychological health benefits in a wide range of populations [19-22]. Various stress management techniques have been applied and evaluated in diverse populations over the last decades in in-person settings or digital interventions. Active techniques, such as physical activity, can lead to a reduced perception of stress. Regular endurance and strength training, as well as yoga, have been shown to be effective in reducing stress [23-25] as well as acting as buffer against stress appraisal in times of elevated stress [25-27]. Similar results can be found for breathing exercises $[28,29]$ and mindfulness training [30,31], with heterogeneous results for meditation exercises [32,33]. However, these active stress management techniques require regular practice. In comparison, passive but effective ways of managing stress and improving well-being are wellness and sauna [34] and spending time in nature $[35,36]$.

In this study, we define the subjective ability to apply and perform such stress management techniques according to personal demands and stress level as stress management competencies. It should, however, be noted that highly stressed individuals are less likely to engage in mental health promoting activities [37-40]. Consequently, families reporting high stress levels presumably also have less stress management competencies. Thus, low-threshold options are needed (1) to support family members experiencing high levels of stress and (2) to teach stress management techniques.

\section{Tailoring in Mobile Health Stress Reduction Interventions}

In an increasingly computer-educated European population, information and communication technology might provide unique and low-threshold opportunities to engage parents and families in mobile health (mHealth)-related services and encourage behavior change, to improve health and reduce stress [41-43].

New concepts, such as the PSYCHE system [44], have emerged as technology aids in order to improve or sustain mental health or stress monitoring [45]. Such wearables include personal health records and are designed to encourage health-related behaviors. Various mobile interventions with different guidance formats (eg, self-help, adherence-focused, eCoaching) have been developed to date and have been shown to be effective in the treatment of diabetes [46], depression [42,47], or sleep disorders [48]. Moreover, web-based stress management interventions seem promising for the treatment and prevention of detrimental stress-related outcomes [49]. Nevertheless, 2 meta-analyses $[42,49]$ show that apps incorporating cognitive behavioral therapy or aspects of mindfulness training yield heterogeneous results. In fact, one of the biggest concerns about the usage of mobile interventions for health promotion is low adherence, which can be associated with reduced effectiveness [50,51]. For this reason, research has called for the examination of suitable components that could help to overcome this challenge.

Tailoring [52] was identified as having positive effects on the health outcomes of web-based interventions. Tailoring is defined as

any combination of information or change strategies
intended to reach one specific person, based on
characteristics that are unique to that person, related
to the outcome of interest, and have been derived from
an individual assessment. [53]

A meta-analysis on tailored print health behavior change interventions has demonstrated that tailored messages were superior compared to generic messages and were associated with larger effect sizes [52]. Moreover, variables such as gender or ethnicity did not moderate this effect which underlines the potential of tailored health communication to raise health-related awareness and knowledge about health for various target populations. To further capture the impact of tailoring, research has expanded to using the web as delivery mode, which again demonstrated the superiority against nontailored interventions $[54,55]$. Next to personalized messages, tailored web-based interventions often include gamification elements such as receiving rewards or social comparisons [56]. A comprehensive systematic review identified engagement promotion and enhancement of effectiveness as main reasons for the application of gamification [57]. Another systematic review on gamification demonstrated that, on average, only one gamification element, such as stories, themes, or display of progress was applied in web-based mental health interventions, with a maximum of 3 applied [56]. Altogether, these studies underline the vast opportunities for tailoring and the inclusion of gamification features and that users might perceive such interventions as 
more personally relevant and credible which again could have a significant impact on health outcomes.

Research on tailored web-based stress management interventions is scarce, yet tailoring could be an effective tool to empower users in their stress management skills and to reinforce self-determined health-related behaviors.

\section{Personality Traits}

On the other hand, studies show that certain personality traits are associated with specific coping behaviors [58,59] and app usage behaviors $[60,61]$, as well as the response to gamification elements [62]. Individuals with personality factors such as high neuroticism, for example, show more vulnerability toward high stress values and problem coping strategies such as wishful thinking, withdrawal, and emotion-focused coping [58,59]. Notably, personality might predict coping strategies in highly stressed samples more accurately than in less stressed samples [58]. Furthermore, conventional personality theories such as the Big Five Personality theory focus on cognitive or emotional contents to explain motivation and self-regulation. The Personality System Interaction (PSI) theory, on the other hand, focuses on:

\section{functional relationships among affective and cognitive macrosystems, i.e., the dynamic processes that underlie human mental functioning [63]}

and might be more suitable to detect and predict self-regulation and volitional aspects of health behavior. PSI theory distinguishes between 2 emotional-(1) the need for stimulation and (2) the need for security-and 2 cognitive systems-(1) the need for information and (2) information processing [64]. Meixner et al [65] investigated the associations between personality traits assessed via PSI theory, interest in app-based monitored physical activity goals, app features, and gamification in order to create tailored mHealth content and found no significant interaction. Furthermore, they concluded that the problem of inactive participants should, in fact, be addressed with app features and gamification elements in accordance with their prior defined goals rather than with their personality traits. Nevertheless, with respect to earlier studies suggesting personality traits being associated with higher stress vulnerability and potentially different stress management competencies, we hypothesize that the results by Meixner et al [65] might not be transferable to stress outcomes and tailored app features.

\section{Study Objectives}

To develop and implement a tailored mobile app that appropriately reaches vulnerable und highly stressed families in order to improve their stress management competencies, the following aspects should be addressed: (1) existing stress management techniques and perceived stress management competencies in families, (2) the influence of personality traits, and (3) potentially suitable features for a mobile stress management intervention such as gamification and (4) defined goals of interest in order to individually manage stress.

Previous studies have focused on evaluation of the usage and tailoring effectiveness; however, evidence on the assessment of users' needs and preferences is limited. Given the adverse impact of low adherence on treatment outcomes, understanding technological and content-related factors is crucial for the design and large-scale implementation of app-based stress reduction interventions into routine health care, and ultimately, to help users to interact in a health-promoting way. With respect to the health impairing consequences of high stress levels for each family member, it seems highly relevant to evaluate the families' needs and preferences for mHealth approaches.

Therefore, the aim of this exploratory study was to identify the requirements of an individualized app to reduce stress in a cohort of highly stressed families that have low stress management skills.

The main research questions were (1) Which characteristics can be identified that describe stressed individuals with low stress competency? (2) Which app features and gamification elements are of the most interest for highly stressed participants with low stress-management competency? (3) Which app features and gamification elements are relevant for different types of stress management goals?

\section{Methods}

\section{Study Design}

This cross-sectional study was part of a project that aims to develop a tailored mHealth intervention for family members and to design health promotion in a sustainable manner. This study was approved by the University of Hamburg ethics committee (file reference: AZ: 2019_270).

\section{Sample}

Every family insured by a small German health insurance cooperative (approximately 18,000 families) was invited by post to participate in a web-based survey. Participation in the study was voluntary, in accordance with the principles for medical research involving humans, and participation was not rewarded in any way. The questionnaire development process included several team-internal evaluation procedures and was implemented using Questback software [66], which allowed individual access via $\mathrm{QR}$ code. To avoid bias due to involuntary disclosure of sensitive information, there was a no disclosure option for each question. There were no mandatory questions for data protection reasons.

\section{Measures}

The questionnaire is available as Multimedia Appendix 1.

\section{Sociodemographic and Health Variables (8 items)}

Age in years (1 item) and gender (1 item) were assessed. In order to provide a holistic framework, the concept health behavior was based on self-assessment in the dimensions of physical activity ( 2 items), dietary behavior ( 2 items), and stress (2 items).

For dietary behavior and physical activity, in each case, 2 questions from the CALO-RE taxonomy of behavior change [67] and the Baecke questionnaire [68] for measuring habitual physical activity were used in combination with the reference values of the World Health Organization [69] and the German Society for Nutrition [70]. 
A health behavior index was developed based on the physical activity, dietary behavior, and stress questions. For this purpose, each question was first evaluated on a scale of not achieved (0), partially achieved (1) and achieved (2) based on the reference values mentioned above. These values were added, resulting in a score between 0 and 12-if all questions were consistent with the proposed reference values in all 3 dimensions, a person reached an overall health index of 12 . This means that the higher the health index, the more health-promoting a person's behavior.

\section{Personally Defined Goals of Interest for Stress Management (10 items)}

The following items were extracted from qualitative interviews: performance of meditation exercises, performance of breathing exercises, performance of yoga exercises, performance of mindfulness exercises, performance of relaxation exercises, improvement of stress management competencies, improvement of the ability to perform stress management techniques from anywhere, improvement of personal resilience to stress, spending time in nature, benefit from wellness and sauna offers. We first conducted interviews and then developed a quantitative survey with items extracted from the interviews. A query of the interest for these items was conducted using multiple checkboxes.

\section{Personality Variables (16 items)}

The personality questions were derived from previous qualitative interviews and checked for construct validity using the Visual Questionnaire [65]. The personality analysis included health-specific questions, which resulted in a manifestation of 4 personality dimensions (need for security, information acquisition, need for stimulation, and information processing). Each dimension was described by 4 items, each rated on a 6-point Likert scale that ranged from 1 (agree) to 6 (disagree).

\section{App Feature Variables (9 items)}

These variables were integrated into the web-based survey to identify tailoring requirements in accordance with our exploratory approach. The questions focused on preferences, ideas, and needs of the respondents in order to design an app in a user-friendly way that was adapted to their needs. The items were individualization of app content, fulfilling common weekly goals and tasks, connecting the app with wearables, increasing knowledge about a healthy lifestyle, suggestions for activities with the family, diaries for documentation and development of strategies, reminders of goals, informational or instructional videos, and analog format for children. Each item was rated by participants on a 6-point scale that ranged from 1 (totally irrelevant) to 6 (totally relevant).

\section{Gamification Feature Variables (14 items)}

Questions asking which gamification elements respondents found appealing - comparison with others, in a ranking or on a high score list; controlling and checking progress; collecting points for performance; collecting shared points with other family members; receiving awards, recognition, or encouragement; monetary incentives for achieving goals; linking to the bonus program of the health insurance company; designing an avatar; completing tasks under time pressure, for example, a countdown; advancing to another level or increasing the level of difficulty; sharing and comparing my achieved goals with others; an accompanying storyline; receiving auditory, haptic, or visual feedback; and rating other family members-were rated on a 6-point scale from 1 (would not appeal to me) to 6 (would appeal to me very much). Similarly, these were integrated into the web-based survey in an exploratory manner.

\section{Procedures}

The web-based questionnaire (EFS Questback; 2019 version [66]) was preceded by participant information including instructions on anonymity, voluntariness, and data privacy. The participants received an invitation by post to complete the questionnaire. Completing the questionnaire took approximately 30 minutes. Only fully completed surveys were included in analysis.

\section{Statistical Analysis}

We used SPSS software (version 27.0; IBM Corp) for statistical analyses.

\section{Step 1}

All variables of the questionnaire that asked for personally defined goals of interest for stress management were factor-analytically reduced to 3 factors (active strategies, general competency, passive strategies) in principal component analysis with Kaiser varimax rotation. Bartlett and Kaiser-Meyer-Olkin measure of sampling adequacy tests were performed to test the suitability of variables for factor analysis.

\section{Step 2}

Perceived stress level and stress-management competency variables were dichotomized in order to identify stressed individuals with low stress competency as a target group. The characteristics of the target group and the rest of the participants were descriptively characterized. We compared groups using analysis of variance.

\section{Step 3}

In order to analyze which app and gamification characteristics are relevant for stressed individuals with low stress competency, the data set was then reduced to only those participants, and to reduce data to relevant variables, all feature and gamification variables with a mean value $<3.5$ in the target group, indicating irrelevant features, or that did not differ significantly between groups were excluded.

\section{Step 4}

We performed 2-way correlation analysis between app and gamification feature variables not excluded in step 3 and the 3 stress reduction target factors (active strategies, general competencies, passive strategies) from step 1.

\section{Step 5}

Three linear regression models were calculated, each with 1 of the 3 target factors for stress management strategies (active strategies, general competencies, passive strategies) as a dependent variable. As independent variables, the remaining variables from step 3 (individualization of app content, fulfilling common weekly goals and tasks, increasing knowledge about a healthy lifestyle, suggestions for activities with the family, 
diaries for documentation and development of strategies, reminders for objectives, informational or instructional videos, and controlling and checking progress) were included.

\section{Power}

In order to be able to demonstrate the anticipated small effect sizes $(<0.05)$ in a multiple linear regression model with $95 \%$ power and 8 predictors, a minimum sample size of 463 was calculated (G*Power; version 3.1 [71]).

\section{Data Exclusion}

Only fully completed questionnaires were included. For bi- and multivariate analysis procedures, list-wise case exclusion was used.

\section{Results}

Of 18,000 families invited by post to participate in the web-based survey, 1008 families completed the questionnaire (a response rate of 17.86\%). The total sample consisted of 599 female, 398 male, and 7 diverse participants; 4 participants did not give any gender information. The average age of respondents was 47.79 years (SD 6.13).

\section{Factor-Analytical Reduction of Personally Defined Goals of Interest for Stress Management}

Both the Bartlett test $\left(\chi_{45}^{2}=2105.563, P<.001\right)$ and measure of sampling adequacy (Kaiser-Meyer-Olkin .854) revealed that 10 stress-related target variables (Figure 1) were suitable for factor analysis. Principal component analysis, with varimax rotation indicated the presence of 2 factors with eigenvalues greater than 1.0, and a 3-factor solution that cumulatively explained $56 \%$ of the variance was chosen based on the scree plot (and theoretical considerations).

Figure 1. Rotated component matrix of the 10 stress-related target variables. Significant correlations are indicated by a continuous line.

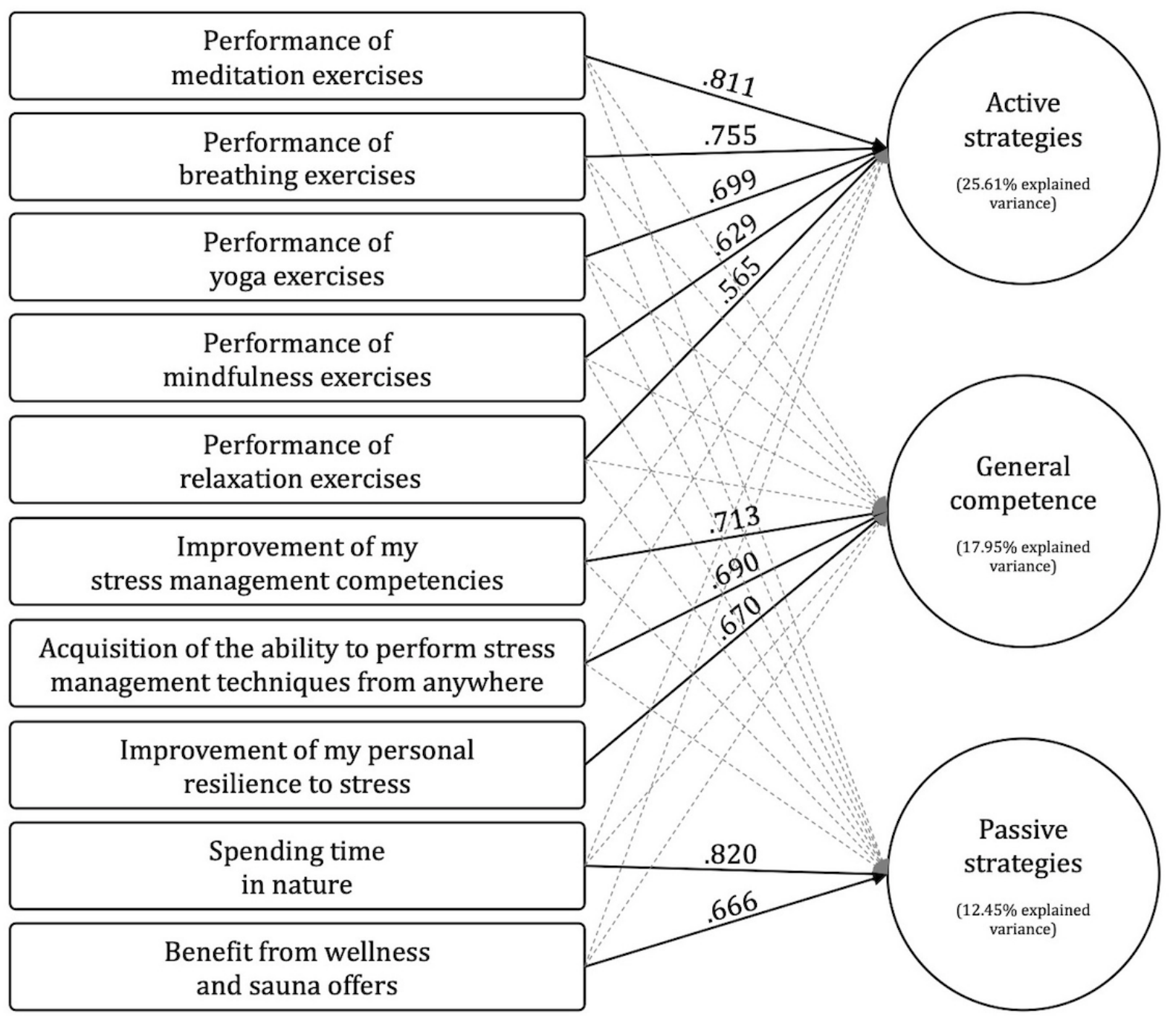

\section{Characteristics}

A comparison of participants with low perceived stress, high stress management skills, or both versus participants with high perceived stress and low stress management (Table 1) demonstrated groups differed in age $\left(F_{1,978}=21.67, P<.001\right.$, $\left.\eta \mathrm{p}^{2}=.022\right)$, health index $\left(F_{1,958}=246.14, P<.001, \eta \mathrm{p}^{2}=.214\right)$, 
active strategies $\left(F_{1,958}=8.03, \quad P=.01, \eta p^{2}=.008\right)$, general competency $\left(F_{1,958}=94.16 P<.001, \eta p^{2}=.086\right)$, information acquisition $\left(\mathrm{F}_{1,971}=14.75, P<.001, \eta \mathrm{p}^{2}=.053\right)$, and need for stimulation $\left(F_{1,981}=54.49, P<.001, \eta p^{2}=.012\right)$. App feature and gamification variables that met Step 3 criteria were individualization of app content $\left(F_{1,977}=8.95, P<.001, \eta \mathrm{p}^{2}=.009\right)$, fulfilling common weekly goals and tasks $\left(F_{1,994}=7.80, P=.01\right.$, $\eta \mathrm{p}^{2}=.008$ ), increasing knowledge about a healthy lifestyle
$\left(F_{1,991}=9.06, P<.001, \eta \mathrm{p}^{2}=.009\right)$, suggestions for activities with the family $\left(F_{1,993}=10.52, P<.001, \eta p^{2}=.010\right)$, diaries for documentation and development of strategies $\left(F_{1,990}=12.43\right.$, $\left.P<.001, \eta \mathrm{p}^{2}=.012\right)$, reminders for objectives $\left(F_{1,995}=4.55, P=.03\right.$, $\left.\eta \mathrm{p}^{2}=.005\right)$, informational or instructional videos" $\left(F_{1,994}=4.71\right.$, $\left.P=.03, \eta \mathrm{p}^{2}=.005\right)$, and controlling and checking progress $\left(F_{1,998}=6.82, P=.01, \eta \mathrm{p}^{2}=.007\right)$. 
Table 1. Comparison of sociodemographic, personality, app feature, and gamification feature variables between groups.

\begin{tabular}{|c|c|c|c|c|c|c|c|}
\hline \multirow[t]{2}{*}{ Variables } & \multicolumn{2}{|c|}{ Nontarget group $(n=548)$} & \multicolumn{2}{|c|}{ Target group $(n=460)$} & \multicolumn{3}{|l|}{ Comparison } \\
\hline & $\mathrm{n}$ & Mean (SD) & $\mathrm{n}$ & Mean (SD) & $F$ test $(d f 1, d f 2)$ & $P$ value & $\eta p^{2}$ \\
\hline \multicolumn{8}{|l|}{ Sociodemographic variables } \\
\hline Age (years) & 534 & $48.62(6.06)$ & 446 & $46.81(6.09)$ & $21.67(1,978)$ & $<.001$ & .022 \\
\hline Gender & & & & & & $\underline{-}^{\mathrm{a}}$ & - \\
\hline Female & 294 & - & 305 & - & - & & \\
\hline Male & 250 & - & 148 & - & - & & \\
\hline Diverse & 3 & - & 4 & - & - & & \\
\hline Health behavior index & 525 & $6.64(1.71)$ & 435 & $5.06(1.36)$ & $246.14(1,978)$ & $<.001$ & .214 \\
\hline \multicolumn{8}{|c|}{ Personally defined goals for stress management } \\
\hline General competency & 548 & $-.26(0.04)$ & 460 & $.32(0.87)$ & $94.16(1,978)$ & $<.001$ & .086 \\
\hline Passive strategies & 548 & $-.02(0.04)$ & 460 & $.03(1.01)$ & $0.537(1,978)$ & .46 & .001 \\
\hline \multicolumn{8}{|l|}{ Personality variables } \\
\hline Need for security & 526 & $3.94(0.83)$ & 448 & $3.87(0.83)$ & $2.18(1,972)$ & .14 & .002 \\
\hline Information acquisition & 525 & $3.66(0.57)$ & 448 & $3.52(0.54)$ & $14.75(1,971)$ & $<.001$ & .015 \\
\hline Need for stimulation & 531 & $3.55(0.62)$ & 452 & $3.26(0.61)$ & $54.49(1,971)$ & $<.001$ & .053 \\
\hline Information processing & 526 & $4.10(0.59)$ & 451 & $4.07(0.58)$ & $0.68(1,975)$ & .41 & .001 \\
\hline \multicolumn{8}{|l|}{ App feature variables } \\
\hline Individualization of app content & 543 & $4.27(1.76)$ & 456 & $4.59(1.57)$ & $8.95(1,978)$ & $<.001$ & .009 \\
\hline Connecting the app with wearables & 534 & $3.02(1.74)$ & 448 & $3.38(1.81)$ & $10.07(1,978)$ & $<.001$ & .010 \\
\hline $\begin{array}{l}\text { Increasing knowledge about a healthy } \\
\text { lifestyle }\end{array}$ & 538 & $4.09(1.62)$ & 455 & $4.38(1.44)$ & $9.06(1,978)$ & $<.001$ & .009 \\
\hline Suggestions for activities with the family & 541 & $3.61(1.61)$ & 454 & $3.94(1.53)$ & $10.52(1,978)$ & $<.001$ & .010 \\
\hline $\begin{array}{l}\text { Diaries for documentation and develop- } \\
\text { ment of strategies }\end{array}$ & 540 & $3.45(1.57)$ & 452 & $3.80(1.51)$ & $12.43(1,978)$ & $<.001$ & .012 \\
\hline Reminders for objectives & 542 & $4.04(1.58)$ & 455 & $4.24(1.47)$ & $4.55(1,978)$ & .03 & .005 \\
\hline Informational or instructional videos & 540 & $4.08(1.60)$ & 456 & $4.30(1.47)$ & $4.71(1,978)$ & .03 & .005 \\
\hline Analog format for children & 548 & $1.72(0.45)$ & 460 & $1.68(0.47)$ & $2.56(1,978)$ & .11 & .003 \\
\hline \multicolumn{8}{|l|}{ Gamification feature variables } \\
\hline $\begin{array}{l}\text { Comparison with others, in a ranking or } \\
\text { on a high score list }\end{array}$ & 544 & $2.26(1.61)$ & 454 & $2.26(1.65)$ & $0(1,976)$ & .98 & 0 \\
\hline Controlling and checking my progress & 546 & $4.25(1.76)$ & 454 & $4.53(1.60)$ & $6.82(1,998)$ & .01 & .007 \\
\hline Collecting points for my performance & 545 & $3.60(1.83)$ & 455 & $3.79(1.78)$ & $2.66(1,998)$ & .10 & .003 \\
\hline $\begin{array}{l}\text { Collecting shared points with other fam- } \\
\text { ily members }\end{array}$ & 541 & $3.50(1.83)$ & 453 & $3.59(1.87)$ & $0.61(1,992)$ & .43 & .001 \\
\hline $\begin{array}{l}\text { Receiving awards, recognition, or encour- } \\
\text { agement }\end{array}$ & 541 & $3.26(1.77)$ & 455 & $3.42(1.76)$ & $2.21(1,994)$ & .14 & .002 \\
\hline $\begin{array}{l}\text { Providing monetary incentives for } \\
\text { achieving goals }\end{array}$ & 536 & $3.52(1.88)$ & 453 & $3.74(1.81)$ & $3.52(1,987)$ & .06 & .004 \\
\hline $\begin{array}{l}\text { Linking to the bonus program of the } \\
\text { health insurance company }\end{array}$ & 541 & $4.16(1.93)$ & 456 & $4.40(1.80)$ & $3.97(1,995)$ & .05 & .004 \\
\hline
\end{tabular}




\begin{tabular}{|c|c|c|c|c|c|c|c|}
\hline \multirow[t]{2}{*}{ Variables } & \multicolumn{2}{|c|}{ Nontarget group $(n=548)$} & \multicolumn{2}{|c|}{ Target group $(n=460)$} & \multicolumn{3}{|l|}{ Comparison } \\
\hline & $\mathrm{n}$ & Mean (SD) & $\mathrm{n}$ & Mean (SD) & $F$ test $(d f 1, d f 2)$ & $P$ value & $\eta \mathrm{p}^{2}$ \\
\hline $\begin{array}{l}\text { Completing tasks under time pressure } \\
\text { (eg, a countdown) }\end{array}$ & 543 & $2.29(1.50)$ & 456 & $2.41(1.58)$ & $1.59(1,997)$ & .21 & .002 \\
\hline $\begin{array}{l}\text { Advancing to another level or increasing } \\
\text { the level of difficulty }\end{array}$ & 542 & $3.22(1.75)$ & 457 & $3.39(1.71)$ & $2.38(1,997)$ & .12 & .002 \\
\hline $\begin{array}{l}\text { Sharing and comparing my achieved } \\
\text { goals with others }\end{array}$ & 542 & $2.18(1.47)$ & 456 & $2.22(1.50)$ & $0.22(1,996)$ & .64 & 0 \\
\hline An accompanying storyline & 541 & $2.65(1.70)$ & 454 & $2.73(1.64)$ & $0.52(1,993)$ & .47 & .001 \\
\hline $\begin{array}{l}\text { Receiving auditory, haptic, or visual } \\
\text { feedback }\end{array}$ & 539 & $3.06(1.73)$ & 455 & $3.27(1.69)$ & $3.9(1,992)$ & .05 & .004 \\
\hline Rating other family members & 539 & $2.43(1.60)$ & 454 & $2.46(1.62)$ & $0.05(1,991)$ & .82 & 0 \\
\hline
\end{tabular}

${ }^{\mathrm{a} D a t a}$ not provided.

\section{Correlations Between Personally Defined Goals of Interest for Stress Management and App Features in the Target Group}

The personally defined active strategies factor was correlated with 5 of the 8 features (increasing knowledge about a healthy lifestyle, suggestions for activities with the family, diaries for documentation and development of strategies, reminders for objectives, and informational or instructional videos) (Table 2). The general competency factor was correlated with fulfilling common weekly goals and tasks, diaries for documentation and development of strategies, and reminders for objectives. The passive strategies factor showed the lowest correlations with the features; it was only correlated with suggestions for activities with the family and diaries for documentation and development of strategies. While some features were correlated with several target factors, others were specific to one factor.

Table 2. Correlations between personally defined goals and app features in stressed individuals with low stress competency.

\begin{tabular}{|c|c|c|c|c|c|c|c|c|c|}
\hline \multirow[t]{2}{*}{ Feature variables ${ }^{\mathrm{a}}$} & \multicolumn{3}{|c|}{ Active strategies } & \multicolumn{3}{|c|}{ General competency } & \multicolumn{3}{|c|}{ Passive strategies } \\
\hline & $r$ & $P$ value & $\mathrm{n}$ & $r$ & $P$ value & $\mathrm{n}$ & $r$ & $P$ value & $\mathrm{n}$ \\
\hline Individualization of app content & 0.044 & .35 & 456 & 0.037 & .43 & 456 & 0.076 & .11 & 456 \\
\hline Fulfilling common weekly goals and tasks & 0.086 & .07 & 455 & 0.107 & .02 & 455 & 0.068 & .15 & 455 \\
\hline Increasing knowledge about a healthy lifestyle & 0.143 & .002 & 455 & 0.066 & .16 & 455 & 0.081 & .08 & 455 \\
\hline Suggestions for activities with the family & 0.158 & .001 & 454 & 0.084 & .07 & 454 & 0.152 & .001 & 454 \\
\hline $\begin{array}{l}\text { Diaries for documentation and development of } \\
\text { strategies }\end{array}$ & 0.136 & .004 & 452 & 0.104 & .03 & 452 & 0.125 & .008 & 452 \\
\hline Reminders for objectives & 0.145 & .002 & 455 & 0.135 & .004 & 455 & 0.048 & .30 & 455 \\
\hline Informational or instructional videos & 0.201 & $<.001$ & 456 & 0.090 & .05 & 456 & 0.061 & .19 & 456 \\
\hline Controlling and checking progress & 0.030 & .52 & 454 & 0.034 & .47 & 454 & 0.005 & .92 & 454 \\
\hline
\end{tabular}

${ }^{a}$ All significant correlations were considered to have a small effect.

\section{Integration of the Feature Variables in Linear Regression Models}

We found that the correlations were partially eliminated in multivariate models (Table 3 ). For the active strategies factor, only information or instructional videos had a significant effect
$(P=.02)$. The general competency factor showed none, and the passive strategies factor showed a significant effect for suggestions for planning possible activities with the family $(P=.01)$ and diaries for documentation and development of strategies $(P=.03)$. 
Table 3. Integration of the feature variables in 3 linear regression models.

\begin{tabular}{|c|c|c|c|c|c|c|}
\hline \multirow[t]{2}{*}{ Feature variables } & \multicolumn{2}{|c|}{ Active strategies } & \multicolumn{2}{|c|}{ General competency } & \multicolumn{2}{|c|}{ Passive strategies } \\
\hline & $\beta$ & $P$ value & $\beta$ & $P$ value & $\beta$ & $P$ value \\
\hline Individualization of app content & -.085 & .21 & -.042 & .54 & .013 & .85 \\
\hline Fulfilling common weekly goals and tasks & .003 & .97 & .055 & .47 & .025 & .74 \\
\hline Increasing knowledge about a healthy lifestyle & .022 & .75 & -.008 & .91 & -.026 & .70 \\
\hline Suggestions for activities with the family & .085 & .20 & .005 & .94 & .174 & .01 \\
\hline $\begin{array}{l}\text { Diaries for documentation and development of } \\
\text { strategies }\end{array}$ & .051 & .45 & .014 & .84 & .149 & .03 \\
\hline Reminders for objectives & .063 & .46 & .152 & .08 & -.129 & .13 \\
\hline Informational or instructional videos & .154 & .02 & .023 & .73 & .023 & .73 \\
\hline Monitoring and checking progress & -.099 & .11 & -.086 & .18 & -.072 & .25 \\
\hline
\end{tabular}

\section{Discussion}

\section{Principal Findings}

The main goal of this cross-sectional study was to identify the requirements for an app that addresses stress management competencies in a cohort of highly stressed family members. We analyzed the characteristics of the target group, their individualized interests in app features and gamification aspects, their personality traits, and different types of personally defined goals.

Almost half of the study sample was identified as the high-risk population-stressed individuals with low stress competency. This underlines the importance of this study's aim. Furthermore, this group's size reflects the ever-increasing proportion of people who feel unable to effectively cope with stressors in their everyday and work-life situations, which is why the World Health Organization classified stress as the health epidemic of the 21 st century and called for prevention strategies [72]. As expected, further analysis of the target group revealed a lower health index - a marker for individual health behavior based on physical activity, dietary behavior, and stress management- than that of the group with lower perceived stress levels. This finding is in line with those of prior studies, indicating that highly stressed individuals are less likely to engage in mental health promoting activities [37-40].

Notably, the target group also differed in their personally defined goals of interest for stress management. The parents who stated that they experience high stress and have low stress management competency aimed to achieve general competencies such as improvement of stress management competencies, acquisition of the ability to perform stress management techniques from anywhere, and improvement of personal resilience to stress. The nontarget group, however, aimed to achieve active strategies including performance of yoga exercises. This highlights the need to differentiate between the groups when developing and implementing mobile solutions to improve stress management competency. According to our results, the target group did not formulate specific goals but tended to have unspecific, general goals. Therefore, one might speculate that participants with subjectively higher stress levels and lower stress management competencies need more help with goal setting and more information about which strategies might reduce stress. These results further emphasize the need for tailored app features for highly stressed families. In line with Control Theory, behavior change techniques, such as goal setting, have been associated with increased intervention effects [73,74]. A study [75] evaluated a newly developed internet-based stress management intervention in a waitlist-controlled randomized trial that included principles for health behavior change such as goal setting, action planning, and coping planning for reducing stress in employees with elevated stress levels; their results showed significantly large effect differences between the intervention and waitlist control group for perceived stress at posttest. Goal-setting techniques features might thus be promising for the individual needs of stressed individuals with low stress competency.

The analysis of specific app features revealed further differences between the 2 groups regarding their app-related interests. The target participants, with low stress management competencies, indeed showed higher ratings for app features that can be used as goal-setting techniques: weekly goal and task achievements, diaries for documentation, and development of strategies and reminders for objectives. Furthermore, they had higher ratings for content individualization, connecting wearables to the app, increasing knowledge about a healthy lifestyle, suggestions for activities with the family, and informational or instructional videos. Overall, these results indicate that users identified as the high-risk population, with low stress-management competencies and high perceived stress levels, wish for features that facilitate the usage of the stress management apps. These requested features can be primarily interpreted as a need for coaching and instruction. In fact, such guided interventions have been shown to be more effective compared with unguided interventions [76]. Moreover, studies suggest guidance is conducive to the effectiveness of stress management interventions [49]. The support that might be provided in eHealth interventions can be technical or content-related, in order to ensure the correct usage [77].

A comprehensive systematic review [57] has established engagement promotion and enhancement of effectiveness as main reasons for the use of gamification in mental health promotion. In an attempt to meet this call, our study investigated the participant's interest in such elements. Nevertheless, among 
gamification feature variables, only controlling and checking progress met relevance criteria. This leads to the assumption that the interest in gamification elements is mostly independent of perceived stress competencies and stress levels. The greater interest of the target group in tracking features of their progress further underpins the assumed need for coaching and instruction as well as goal setting.

Interestingly, persons reporting high stress levels and low stress management skills were younger than participants with lower self-reported stress and differed significantly in 2 personality traits variables. Specifically, their personality structure indicated lower scores in information acquisition $(P<.001)$ and need for stimulation $(P<.001)$. According to PSI theory, stressed individuals with low stress competency thus have more selective information acquisition and lower needs for stimulation than the nontarget group members [64]. Kuhl [78] describes individuals with selective information acquisition in accordance with Jung [79] by pointing out their analytical and structured thinking and their intuitive ability to control their behavior Unconscious perception and behavior programs may consequently support them. A low need for stimulation, in contrast, indicates less action-oriented and more introverted behavior [64]. This is frequently associated, in other studies $[80,81]$, with the occurrence of anxiety, stress, and depression. Thus, our results suggest that these 2 personality traits are vital for the perception and management of stress. Literature repeatedly demonstrated this influence of personality traits on stress perception $[82,83]$. For the development of an app to improve stress management skills, individualization of the content based on personality structure will address individuals in the target group more adequately. The content should be tailored to people with selective information acquisition and a low need for stimulation. This might be achieved by a minimalistic user interface, decreasing the participants' stimulation, thereby focusing their attention on the essential contents. Ervasti et al [84] were able to show, with a study on the influence of personality on interest in stress apps that high neuroticism levels (originated in the Big Five theory, but conceptually comparable to low stimulation need in PSI theory) were positively correlated with interest in stress management apps, which is analogous to the results of this study. The predictive value of neuroticism on stress perception was also highlighted in a comprehensive meta-analysis [58].

Furthermore, it appears that interest in some features was higher, depending on specific personally defined goals of interest. While multiple correlations were found between personally defined goals and app features, correlations were partially eliminated in multivariate models. Nevertheless, our results indicate that the probability of interest in informational or instructional videos was higher when active goals had been set. Similarly, interest in suggestions for family activities and diaries was higher when personally defined goals yielded passive strategies.

Our results support the theory that creating a stress management app requires tailored content to address the differences in perceived stress levels, stress competencies, and personality traits. These findings build on those of Lustria et al [54], who pointed out that presenting general health information without considering individual needs or personal relevance may substantially limit the extent of health behavior change. Our study substantiate this call for individualized messaging based on preassessment of key individual-difference variables by reinforcing the notion that highly vulnerable families with low perceived stress competency need an individualized app content, additionally tailoring different personality types. Tailoring works by increasing the personal relevance of health messages [85] and holds promise.

\section{Limitations and Future Research Directions}

One limitation of the study is that only individual parents were surveyed. Assessing more than one family member could not be realized at this stage of the project but will be aimed for in future studies. With respect to spill-over effects of perceived stress across family members [8-10], a holistic analysis of requirements of an app that targets the entire family is needed.

A further limitation is that the identification of our target group was only based on 2 items. This was due to practical reasons and the length of the existing survey in a larger research project. The results presented and discussed in this paper can, thus, only be regarded as exploratory and should be replicated using validated scales such as the Perceived Stress Scale [86]. Nevertheless, because of the large sample size, our results underpin those from existing research, reinforcing the notion of tailoring in the development of web-based stress management interventions.

Future research should bring these preliminary data into practice and develop and evaluate an app that adequately addresses the stress level and stress competency as well as personality traits and personal goals of the user. Furthermore, there is still no evidence to support whether already existing apps are well accepted by our target group and whether these apps provide motivating factors for long-term use to build and maintain stress management skills. For this reason, further studies on the sustainable development of apps and the support of behavior change processes, in the course of stress management, should identify the situations and conditions that can have an impact on work-life stress, coping, and goals of individual family members.

There is also a need for further research in this area to provide sustainable evidence for features and gamification elements with the aim of developing age- and gender-specific stress coping skills and, if necessary, to enable transfer to other digital media.

\section{Practical Implications}

Nevertheless, there are some important practical implications. Health authorities and mHealth or app developers should take our findings into account when planning and implementing tailored app-based mental health promotion interventions for families. In a first step, target group identification is necessary. The target sample-highly stressed families with low stress competencies, in this case-can be characterized by age, gender, health behavior, and personality. The design of the app, as well as its promotion, should address the unique characteristics of the target group, for example, in this case, a minimalistic user interface that decreases stimulation. In a second step, the app should be designed in such a way that individual setting of a 
stress management goal is possible. These self-defined goals, relevant app and gamification elements (Figure 2). defined beforehand, represent specific demands and wishes for

Figure 2. Planned development of a tailored app to increase stress management competencies within families, based on our results. In step 2, the continuous lines depict the significant effects of the calculated linear regression models whilst the dashed lines represent significant correlations.

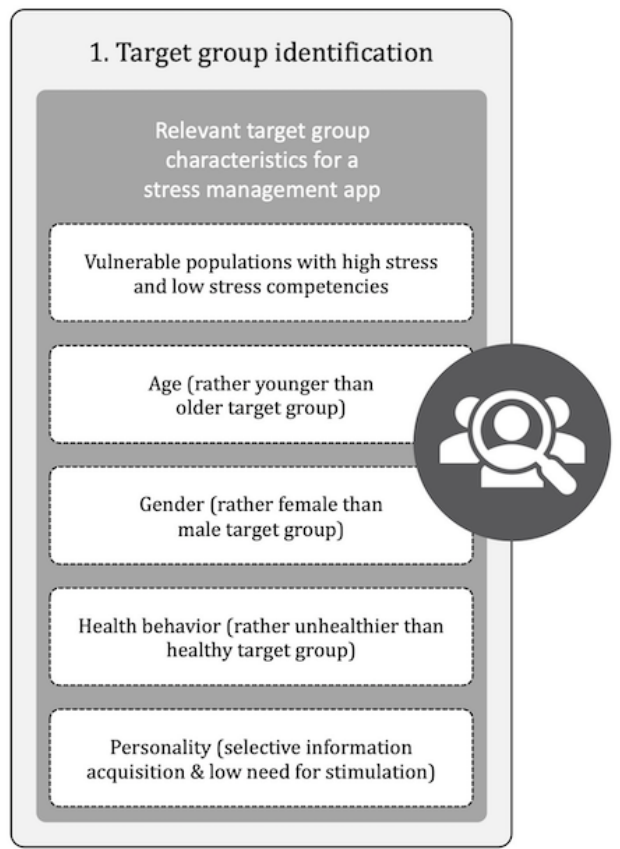

\section{Conclusions}

The results of this cross-sectional study show that, in order to develop an app to increase stress management competencies within families, the content should be based on preassessed of competencies, goals, and personality traits of the potential user, and thus, tailored to the user's needs. Highly stressed parents with low stress management skills want features in an app that make it easier to use and include goal setting techniques. In fact, a need for coaching and instruction was identified, which

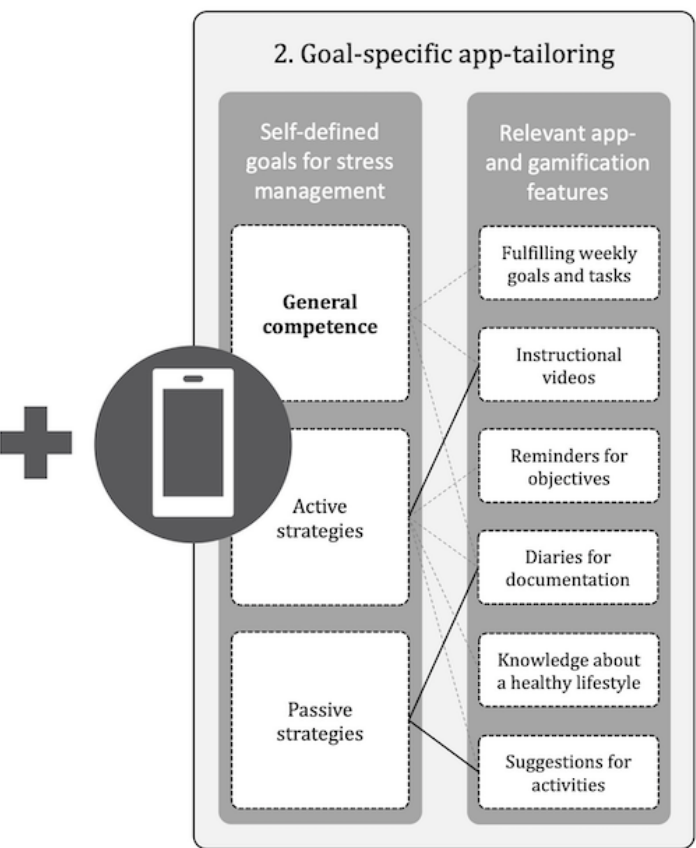

underpinned prior research showing that guided stress management interventions have more promising results.

This study delivers first results and directions to inform further research in the growing field of mobile and web-based solutions in mental health care. The relationship between integrated elements of behavior change techniques, the usage of gamification elements, and most notably, tailoring of the content of a web-based intervention and the resulting health behavior change show promise that is urgently needed with respect to increasing stress levels and its associated adverse health effects.

\section{Acknowledgments}

This study was part of a project (CASPAR Coaching App for Setting Oriented Prevention Work) supported by a German health insurance company. The views expressed in this paper are those of the authors and may not be shared by the funding agencies. The study data were analyzed independently of the study sponsors. This sponsor did not and does not play a role in the design of the study, the data analysis, the reporting of the results, or the decision to submit the manuscript for publication.

\section{Conflicts of Interest}

None declared.

\section{Multimedia Appendix 1}

Web-based questionnaire on health app tailoring requirements (translated from German).

[DOCX File, 20 KB-Multimedia Appendix 1]

\section{References}

1. Åkerstedt T. Psychosocial stress and impaired sleep. Scand J Work Environ Health 2006 Dec;32(6):493-501 [FREE Full text] [doi: 10.5271/sjweh.1054] [Medline: 17173205]

2. Bhatia V, Tandon RK. Stress and the gastrointestinal tract. J Gastroenterol Hepatol 2005 Mar;20(3):332-339. [doi: 10.1111/j.1440-1746.2004.03508.x] [Medline: 15740474] 
3. Golden SH. A review of the evidence for a neuroendocrine link between stress, depression and diabetes mellitus. Curr Diabetes Rev 2007 Nov;3(4):252-259. [doi: 10.2174/157339907782330021] [Medline: 18220683]

4. Richardson S, Shaffer JA, Falzon L, Krupka D, Davidson KW, Edmondson D. Meta-analysis of perceived stress and its association with incident coronary heart disease. Am J Cardiol 2012 Dec 15;110(12):1711-1716 [FREE Full text] [doi: 10.1016/j.amjcard.2012.08.004] [Medline: 22975465]

5. Hammen C. Stress and depression. Annu Rev Clin Psychol 2005;1:293-319. [doi: 10.1146/annurev.clinpsy.1.102803.143938] [Medline: 17716090]

6. Reupert A, Maybery D. Families affected by parental mental illness: a multiperspective account of issues and interventions. Am J Orthopsychiatry 2007 Jul;77(3):362-369. [doi: 10.1037/0002-9432.77.3.362] [Medline: 17696664]

7. Melchior M, Berkman LF, Niedhammer I, Zins M, Goldberg M. The mental health effects of multiple work and family demands. a prospective study of psychiatric sickness absence in the French GAZEL study. Soc Psychiatry Psychiatr Epidemiol 2007 Jul;42(7):573-582 [FREE Full text] [doi: 10.1007/s00127-007-0203-2] [Medline: 17530152]

8. Carnes AM. Bringing work stress home: the impact of role conflict and role overload on spousal marital satisfaction. $\mathrm{J}$ Occup Organ Psychol 2016 Dec 15;90(2):153-176 [FREE Full text] [doi: 10.1111/joop.12163]

9. Grzywacz JG, Almeida DM, McDonald DA. Work-family spillover and daily reports of work and family stress in the adult labor force. Fam Relat 2002 Aug;51(1):28-36 [FREE Full text] [doi: 10.1111/j.1741-3729.2002.00028.x]

10. Westman M. Stress and strain crossover. Hum Relat 2016 Apr 22;54(6):717-751. [doi: 10.1177/0018726701546002]

11. McMinn AM, Griffin SJ, Jones AP, van Sluijs EMF. Family and home influences on children's after-school and weekend physical activity. Eur J Public Health 2013 Oct;23(5):805-810 [FREE Full text] [doi: 10.1093/eurpub/cks 160] [Medline: 23172732]

12. Arredondo EM, Elder JP, Ayala GX, Campbell N, Baquero B, Duerksen S. Is parenting style related to children's healthy eating and physical activity in Latino families? Health Educ Res 2006 Dec;21(6):862-871. [doi: 10.1093/her/cyl110] [Medline: 17032706 ]

13. Webb HJ, Zimmer-Gembeck MJ, Scuffham PA, Scott R, Barber B. Family stress predicts poorer dietary quality in children: examining the role of the parent-child relationship. Inf Child Dev 2018 Feb 08;27(4):e2088. [doi: 10.1002/icd.2088]

14. Smolka A, Rupp M. Die Familie als Ort der Vermittlung von Alltags- und Daseinskompetenzen. In: Harring M, Rohlfs C, Palentien C, editors. Perspektiven der Bildung: Kinder und Jugendliche in formellen, nicht-formellen und informellen Bildungsprozessen. Wiesbaden: VS Verl. für Sozialwiss; 2007:219-236 URL: https://link.springer.com/chapter/10.1007/ 978-3-531-90637-9 12

15. Xu H, Wen LM, Rissel C. Associations of parental influences with physical activity and screen time among young children: a systematic review. J Obes 2015;2015:546925 [FREE Full text] [doi: 10.1155/2015/546925] [Medline: 25874123]

16. Borrmann A, Mensink GBM, KiGGS Study Group. [Fruit and vegetable consumption by children and adolescents in Germany: results of KiGGS wave 1]. Bundesgesundheitsblatt Gesundheitsforschung Gesundheitsschutz 2015 Sep;58(9):1005-1014. [doi: 10.1007/s00103-015-2208-4] [Medline: 26141246]

17. Braveman P, Gottlieb L. The social determinants of health: it's time to consider the causes of the causes. Public Health Rep 2014 Aug 1;129 Suppl 2(12):19-31 [FREE Full text] [doi: 10.1177/00333549141291S206] [Medline: 24385661]

18. Geene R, Boger M. Literatur- und Datenbankrecherche zu Gesundheitsförderungs- und Präventionsansätzen bei Alleinerziehenden und Auswertung der vorliegenden Evidenz. GKV-Spitzenverband. 2017. URL: https://www. gkv-buendnis.de/fileadmin/user upload/Literaturrecherche Alleinerziehende Geene 2017.pdf [accessed 2020-11-30]

19. Baer RA. Mindfulness training as a clinical intervention: a conceptual and empirical review. Clin Psychol (New York) 2003;10(2):125-143. [doi: 10.1093/clipsy.bpg015]

20. Fjorback LO, Arendt M, Ornbøl E, Fink P, Walach H. Mindfulness-based stress reduction and mindfulness-based cognitive therapy: a systematic review of randomized controlled trials. Acta Psychiatr Scand 2011 Aug;124(2):102-119. [doi: 10.1111/j.1600-0447.2011.01704.x] [Medline: 21534932]

21. Grossman P, Niemann L, Schmidt S, Walach H. Mindfulness-based stress reduction and health benefits. a meta-analysis. J Psychosom Res 2004 Jul;57(1):35-43. [doi: 10.1016/S0022-3999(03)00573-7] [Medline: 15256293]

22. Querstret D, Morison L, Dickinson S, Cropley M, John M. Mindfulness-based stress reduction and mindfulness-based cognitive therapy for psychological health and well-being in nonclinical samples: a systematic review and meta-analysis. Int J Stress Manag 2020 Nov;27(4):394-411. [doi: 10.1037/str0000165]

23. Avila-Palencia I, de Nazelle A, Cole-Hunter T, Donaire-Gonzalez D, Jerrett M, Rodriguez DA, et al. The relationship between bicycle commuting and perceived stress: a cross-sectional study. BMJ Open 2017 Jun 23;7(6):e013542 [FREE Full text] [doi: 10.1136/bmjopen-2016-013542] [Medline: 28645948]

24. Bischoff LL, Otto A, Hold C, Wollesen B. The effect of physical activity interventions on occupational stress for health personnel: a systematic review. Int J Nurs Stud 2019 Sep;97:94-104. [doi: 10.1016/j.ijnurstu.2019.06.002] [Medline: 31234106]

25. von Haaren B, Ottenbacher J, Muenz J, Neumann R, Boes K, Ebner-Priemer U. Does a 20-week aerobic exercise training programme increase our capabilities to buffer real-life stressors? a randomized, controlled trial using ambulatory assessment. Eur J Appl Physiol 2016 Feb;116(2):383-394. [doi: 10.1007/s00421-015-3284-8] [Medline: 26582310] 
26. Sloan RP, Shapiro PA, DeMeersman RE, Bagiella E, Brondolo EN, McKinley PS, et al. Impact of aerobic training on cardiovascular reactivity to and recovery from challenge. Psychosom Med 2011;73(2):134-141 [FREE Full text] [doi: 10.1097/PSY.0b013e31820a1174] [Medline: 21257979]

27. Klaperski S, von Dawans B, Heinrichs M, Fuchs R. Effects of a 12-week endurance training program on the physiological response to psychosocial stress in men: a randomized controlled trial. J Behav Med 2014 Dec;37(6):1118-1133. [doi: 10.1007/s10865-014-9562-9] [Medline: 24659155]

28. Ma X, Yue Z, Gong Z, Zhang H, Duan N, Shi Y, et al. The effect of diaphragmatic breathing on attention, negative affect and stress in healthy adults. Front Psychol 2017;8:874 [FREE Full text] [doi: 10.3389/fpsyg.2017.00874] [Medline: 28626434]

29. Hopper SI, Murray SL, Ferrara LR, Singleton JK. Effectiveness of diaphragmatic breathing for reducing physiological and psychological stress in adults: a quantitative systematic review. JBI Database System Rev Implement Rep 2019 Sep;17(9):1855-1876. [doi: 10.11124/JBISRIR-2017-003848] [Medline: 31436595]

30. Khoury B, Sharma M, Rush SE, Fournier C. Mindfulness-based stress reduction for healthy individuals: a meta-analysis. J Psychosom Res 2015 Jun;78(6):519-528. [doi: 10.1016/j.jpsychores.2015.03.009] [Medline: 25818837]

31. Chiesa A, Serretti A. Mindfulness-based stress reduction for stress management in healthy people: a review and meta-analysis. J Altern Complement Med 2009 May;15(5):593-600. [doi: 10.1089/acm.2008.0495] [Medline: 19432513]

32. Huberty J, Green J, Glissmann C, Larkey L, Puzia M, Lee C. Efficacy of the mindfulness meditation mobile app "calm" to reduce stress among college students: randomized controlled trial. JMIR Mhealth Uhealth 2019 Jun 25;7(6):e14273 [FREE Full text] [doi: 10.2196/14273] [Medline: 31237569]

33. Oken BS, Wahbeh H, Goodrich E, Klee D, Memmott T, Miller M, et al. Meditation in stressed older adults: improvements in self-rated mental health not paralleled by improvements in cognitive function or physiological measures. Mindfulness (N Y) 2017 Jun;8(3):627-638 [FREE Full text] [doi: 10.1007/s12671-016-0640-7] [Medline: 28603562]

34. Hussain JN, Greaves RF, Cohen MM. A hot topic for health: results of the global sauna survey. Complement Ther Med 2019 Jun;44:223-234. [doi: 10.1016/j.ctim.2019.03.012] [Medline: $\underline{31126560}$ ]

35. Antonelli M, Barbieri G, Donelli D. Effects of forest bathing (shinrin-yoku) on levels of cortisol as a stress biomarker: a systematic review and meta-analysis. Int J Biometeorol 2019 Aug;63(8):1117-1134. [doi: 10.1007/s00484-019-01717-x] [Medline: 31001682]

36. Hunter MR, Gillespie BW, Chen SY. Urban nature experiences reduce stress in the context of daily life based on salivary biomarkers. Front Psychol 2019;10:722 [FREE Full text] [doi: 10.3389/fpsyg.2019.00722] [Medline: $\underline{31019479]}$

37. Stults-Kolehmainen MA, Sinha R. The effects of stress on physical activity and exercise. Sports Med 2014 Jan;44(1):81-121 [FREE Full text] [doi: 10.1007/s40279-013-0090-5] [Medline: 24030837]

38. Schultchen D, Reichenberger J, Mittl T, Weh TRM, Smyth JM, Blechert J, et al. Bidirectional relationship of stress and affect with physical activity and healthy eating. Br J Health Psychol 2019 May;24(2):315-333 [FREE Full text] [doi: 10.1111/bjhp.12355] [Medline: 30672069]

39. Ng DM, Jeffery RW. Relationships between perceived stress and health behaviors in a sample of working adults. Health Psychol 2003 Nov;22(6):638-642. [doi: 10.1037/0278-6133.22.6.638] [Medline: 14640862]

40. Rao KU, Russel RW. Effects of stress on goal setting behavior. J Abnorm Soc Psychol 1960 Nov;61:380-388. [doi: 10.1037/h0040176] [Medline: 13739530]

41. Chandrashekar P. Do mental health mobile apps work: evidence and recommendations for designing high-efficacy mental health mobile apps. Mhealth 2018;4:6 [FREE Full text] [doi: 10.21037/mhealth.2018.03.02] [Medline: 29682510]

42. Firth J, Torous J, Nicholas J, Carney R, Pratap A, Rosenbaum S, et al. The efficacy of smartphone-based mental health interventions for depressive symptoms: a meta-analysis of randomized controlled trials. World Psychiatry 2017 Oct;16(3):287-298 [FREE Full text] [doi: 10.1002/wps.20472] [Medline: 28941113]

43. Price M, Yuen EK, Goetter EM, Herbert JD, Forman EM, Acierno R, et al. mHealth: a mechanism to deliver more accessible, more effective mental health care. Clin Psychol Psychother 2014;21(5):427-436 [FREE Full text] [doi: 10.1002/cpp.1855] [Medline: 23918764]

44. Lanata A, Valenza G, Nardelli M, Gentili C, Scilingo EP. Complexity index from a personalized wearable monitoring system for assessing remission in mental health. IEEE J Biomed Health Inform 2015 Jan;19(1):132-139. [doi: 10.1109/JBHI.2014.2360711] [Medline: 25291802]

45. Ben-Zeev D, Davis KE, Kaiser S, Krzsos I, Drake RE. Mobile technologies among people with serious mental illness: opportunities for future services. Adm Policy Ment Health 2013 Jul;40(4):340-343 [FREE Full text] [doi: 10.1007/s10488-012-0424-x] [Medline: 22648635]

46. Liang X, Wang Q, Yang X, Cao J, Chen J, Mo X, et al. Effect of mobile phone intervention for diabetes on glycaemic control: a meta-analysis. Diabet Med 2011 Apr;28(4):455-463. [doi: 10.1111/j.1464-5491.2010.03180.x] [Medline: 21392066]

47. Cuijpers P, Kleiboer A, Karyotaki E, Riper H. Internet and mobile interventions for depression: opportunities and challenges. Depress Anxiety 2017 Jul;34(7):596-602. [doi: 10.1002/da.22641] [Medline: 28471479]

48. Cheng SK, Dizon J. Computerised cognitive behavioural therapy for insomnia: a systematic review and meta-analysis. Psychother Psychosom 2012;81(4):206-216. [doi: 10.1159/000335379] [Medline: 22585048] 
49. Heber E, Ebert DD, Lehr D, Cuijpers P, Berking M, Nobis S, et al. The benefit of web- and computer-based interventions for stress: a systematic review and meta-analysis. J Med Internet Res 2017 Feb 17;19(2):e32 [FREE Full text] [doi: 10.2196/jmir.5774] [Medline: 28213341]

50. Beintner I, Jacobi C, Taylor CB. Participant adherence to the internet-based prevention program StudentBodies ${ }^{\mathrm{TM}}$ for eating disorders - a review. Internet Interventions 2014 Mar;1(1):26-32. [doi: 10.1016/j.invent.2014.03.001]

51. Calear AL, Christensen H, Mackinnon A, Griffiths KM. Adherence to the MoodGYM program: outcomes and predictors for an adolescent school-based population. J Affect Disord 2013 May;147(1-3):338-344. [doi: 10.1016/j.jad.2012.11.036] [Medline: 23245469]

52. Lustria MLA, Cortese J, Noar SM, Glueckauf RL. Computer-tailored health interventions delivered over the web: review and analysis of key components. Patient Educ Couns 2009 Mar;74(2):156-173. [doi: 10.1016/j.pec.2008.08.023] [Medline: $\underline{18947966]}$

53. Kreuter MW, Skinner CS. Tailoring: what's in a name? Health Educ Res 2000 Mar;15(1):1-4. [doi: 10.1093/her/15.1.1] [Medline: 10788196]

54. Lustria MLA, Noar SM, Cortese J, Van Stee SK, Glueckauf RL, Lee J. A meta-analysis of web-delivered tailored health behavior change interventions. J Health Commun 2013;18(9):1039-1069. [doi: 10.1080/10810730.2013.768727] [Medline: 23750972]

55. Krebs P, Prochaska JO, Rossi JS. A meta-analysis of computer-tailored interventions for health behavior change. Prev Med 2010;51(3-4):214-221 [FREE Full text] [doi: 10.1016/j.ypmed.2010.06.004] [Medline: 20558196]

56. Brown M, O'Neill N, van Woerden H, Eslambolchilar P, Jones M, John A. Gamification and adherence to web-based mental health interventions: a systematic review. JMIR Ment Health 2016 Aug 24;3(3):e39 [FREE Full text] [doi: 10.2196/mental.5710] [Medline: 27558893]

57. Cheng V, Davenport T, Johnson D, Vella K, Hickie I. Gamification in apps and technologies for improving mental health and well-being: systematic review. JMIR Ment Health 2019 Jun 26;6(6):e13717 [FREE Full text] [doi: 10.2196/13717] [Medline: $\underline{31244479}$ ]

58. Connor-Smith JK, Flachsbart C. Relations between personality and coping: a meta-analysis. J Pers Soc Psychol 2007 Dec;93(6):1080-1107. [doi: 10.1037/0022-3514.93.6.1080] [Medline: $\underline{18072856}$ ]

59. Vollrath M, Torgersen S. Personality types and coping. Pers Individ Dif 2000 Aug;29(2):367-378. [doi: 10.1016/s0191-8869(99)00199-3]

60. Stachl C, Hilbert S, Au J, Buschek D, De Luca A, Bischl B, et al. Personality traits predict smartphone usage. Eur J Pers 2017 Aug 02;31(6):701-722 [FREE Full text] [doi: 10.1002/per.2113]

61. Su J, Dugas M, Guo X, Gao GG. Influence of personality on mhealth use in patients with diabetes: prospective pilot study. JMIR Mhealth Uhealth 2020 Aug 10;8(8):e17709 [FREE Full text] [doi: 10.2196/17709] [Medline: 32773382]

62. Ghaban W, Hendley R. How different personalities benefit from gamification. Interact Comput 2019 Apr 08;31(2):138-153. [doi: 10.1093/iwc/iwz009]

63. Kuhl J. The volitional basis of personality systems interaction theory. Int J Educ Res 2000 Jan;33(7-8):665-703 [REE Full text] [doi: 10.1016/s0883-0355(00)00045-8]

64. Scheffer D, Loerwald D, Mainz D. Messung von impliziten Persönlichkeits-Systemen mit Hilfe der visuellen Testmethode des Visual Questionnaire ViQ. In: Arbeitspapiere der Nordakademie. Elmshorn: Nordakademie - Hochschule der Wirtschaft; Mar 2009.

65. Meixner C, Baumann H, Wollesen B. Personality traits, gamification and features to develop an app to reduce physical inactivity. Information $2020 \mathrm{Jul}$ 19;11(7):367. [doi: 10.3390/info11070367]

66. Questback GmbH. EFS survey. Questback. Cologne URL: https://www.questback.com/de/online-befragungstool/ [accessed 2020-11-30]

67. Hagger M, Keatley D, Chan D. CALO-RE taxonomy of behavior change techniques. In: Inklund RC, Tenenbaum G, editors. Encyclopedia of Sport and Exercise Psychology. Thousand Oaks: SAGE Publications, Inc; 2014:100-104.

68. Baecke JA, Burema J, Frijters JE. A short questionnaire for the measurement of habitual physical activity in epidemiological studies. Am J Clin Nutr 1982 Nov;36(5):936-942. [doi: 10.1093/ajcn/36.5.936] [Medline: 7137077]

69. Global Recommendations on Physical Activity for Health. Geneva: World Health Organization; 2010:2014-2092.

70. 10 guidelines of the German Nutrition Society (DGE) for a wholesome diet. Deutsche Gesellschaft für Ernährung e.V. URL: https://www.dge.de/ernaehrungspraxis/vollwertige-ernaehrung/10-regeln-der-dge/en/ [accessed 2020-12-07]

71. Faul F, Erdfelder E, Lang A, Buchner A. G*Power 3: a flexible statistical power analysis program for the social, behavioral, and biomedical sciences. Behav Res Methods 2007 May;39(2):175-191. [doi: 10.3758/bf03193146] [Medline: 17695343]

72. The Global Burden of Disease 2004 Update. Geneva: World Health Organization; 2008.

73. Michie S, Abraham C, Whittington C, McAteer J, Gupta S. Effective techniques in healthy eating and physical activity interventions: a meta-regression. Health Psychol 2009 Nov;28(6):690-701. [doi: 10.1037/a0016136] [Medline: 19916637]

74. Strecher VJ, Seijts GH, Kok GJ, Latham GP, Glasgow R, DeVellis B, et al. Goal setting as a strategy for health behavior change. Health Educ Q 1995 May;22(2):190-200. [doi: 10.1177/109019819502200207] [Medline: 7622387] 
75. Heber E, Lehr D, Ebert DD, Berking M, Riper H. Web-based and mobile stress management intervention for employees: a randomized controlled trial. J Med Internet Res 2016 Jan 27;18(1):e21 [FREE Full text] [doi: 10.2196/jmir.5112] [Medline: 26818683]

76. Baumeister H, Reichler L, Munzinger M, Lin J. The impact of guidance on internet-based mental health interventions a systematic review. Internet Interv 2014 Oct;1(4):205-215. [doi: 10.1016/j.invent.2014.08.003]

77. Schueller SM, Tomasino KN, Mohr DC. Integrating human support into behavioral intervention technologies: the efficiency model of support. Clin Psychol Sci Pract 2016 Nov 17;24(1):27-45. [doi: 10.1111/cpsp.12173]

78. Kuhl J. Motivation und Persönlichkeit: Interaktionen psychischer Systeme. Göttingen: Hogrefe Verl. für Psychologie; 2001.

79. Jung C. Psychologische Typen. Solothurn: Walter-Verl; 2006.

80. Uliaszek AA, Zinbarg RE, Mineka S, Craske MG, Sutton JM, Griffith JW, et al. The role of neuroticism and extraversion in the stress-anxiety and stress-depression relationships. Anxiety Stress Coping 2010 Jul;23(4):363-381 [FREE Full text] [doi: 10.1080/10615800903377264] [Medline: 19890753]

81. Jylhä P, Melartin T, Isometsä E. Relationships of neuroticism and extraversion with axis I and II comorbidity among patients with DSM-IV major depressive disorder. J Affect Disord 2009 Apr;114(1-3):110-121. [doi: 10.1016/j.jad.2008.06.011] [Medline: $\underline{18687471]}$

82. Cramer C, Binder K. Zusammenhänge von Persönlichkeitsmerkmalen und Beanspruchungserleben im Lehramt. Ein internationales systematisches Review. Z Erziehungswiss 2015 Jan 31;18(1):101-123. [doi: 10.1007/s11618-014-0605-3]

83. Kim LE, Jörg V, Klassen RM. A meta-analysis of the effects of teacher personality on teacher effectiveness and burnout. Educ Psychol Rev 2019;31(1):163-195 [FREE Full text] [doi: 10.1007/s10648-018-9458-2] [Medline: 30930595]

84. Ervasti M, Kallio J, Määttänen I, Mäntyjärvi J, Jokela M. Influence of personality and differences in stress processing among Finnish students on interest to use a mobile stress management app: survey study. JMIR Ment Health 2019 May 13;6(5):e10039 [FREE Full text] [doi: 10.2196/10039] [Medline: 31094358]

85. Hawkins RP, Kreuter M, Resnicow K, Fishbein M, Dijkstra A. Understanding tailoring in communicating about health. Health Educ Res 2008 Jun;23(3):454-466 [FREE Full text] [doi: 10.1093/her/cyn004] [Medline: 18349033]

86. Cohen S, Kamarck T, Mermelstein R. A global measure of perceived stress. J Health Soc Behav 1983 Dec;24(4):385-396. [Medline: $\underline{6668417]}$

\section{Abbreviations \\ mHealth: mobile health \\ PSI: Personality System Interaction}

Edited by R Kukafka; submitted 09.12.20; peer-reviewed by J Kallio, N Fijacko; comments to author 17.02.21; revised version received 24.03.21; accepted 04.05.21; published 30.07.21

Please cite as:

Bischoff LL, Baumann H, Meixner C, Nixon P, Wollesen B

App-Tailoring Requirements to Increase Stress Management Competencies Within Families: Cross-sectional Survey Study

J Med Internet Res 2021;23(7):e26376

URL: https://www.jmir.org/2021/7/e26376

doi: $10.2196 / 26376$

PMID: $\underline{34328439}$

(CLaura Luise Bischoff, Hannes Baumann, Charlotte Meixner, Patricia Nixon, Bettina Wollesen. Originally published in the Journal of Medical Internet Research (https://www.jmir.org), 30.07.2021. This is an open-access article distributed under the terms of the Creative Commons Attribution License (https://creativecommons.org/licenses/by/4.0/), which permits unrestricted use, distribution, and reproduction in any medium, provided the original work, first published in the Journal of Medical Internet Research, is properly cited. The complete bibliographic information, a link to the original publication on https://www.jmir.org/, as well as this copyright and license information must be included. 